\title{
Is FDG-PET/CT Useful for Diagnosing Pulmonary Metastasis in Patients with Soft Tissue Sarcoma?
}

\author{
TOMOHITO HAGI ${ }^{1}$, TOMOKI NAKAMURA ${ }^{1}$, YUICHI SUGINO ${ }^{2}$, TAKAO MATSUBARA ${ }^{1}$, \\ KUNIHIRO ASANUMA ${ }^{1}$ and AKIHIRO SUDO ${ }^{1}$ \\ ${ }^{1}$ Department of Orthopaedic Surgery, Mie University Graduate School of Medicine, Tsu, Japan; \\ ${ }^{2}$ Department of Radiology, Mie University Hospital, Tsu, Japan
}

\begin{abstract}
Background/Aim: In patients with soft tissue sarcoma (STS), distinguishing small metastatic pulmonary nodules from benign ones remains difficult. This study aimed to determine the accuracy of ${ }^{18} \mathrm{~F}$-fluorodeoxyglucose positron emission tomography/computed tomography (FDG$P E T / C T)$ in detecting pulmonary metastasis and identify factors affecting sensitivity with STS. Materials and Methods: The clinical records and chest $C T$ and FDGPET/CT scans of 102 patients with STS were reviewed to determine the presence of pulmonary nodules. Results: A significant relationship was observed between nodule size and maximum standardized uptake value $\left(S U V_{\max }\right)$. For nodules smaller than $5 \mathrm{~mm}$, only 10 out of 76 metastatic pulmonary nodules exhibited FDG accumulation, showing a weak correlation between nodule size and $S U V_{\max }$. Conclusion: The role of FDG-PET/CT in differentiating metastatic from benign pulmonary nodules was unsatisfactory, especially for small nodules. Careful followup using CT scan may still be appropriate for diagnosing pulmonary nodules smaller than $5 \mathrm{~mm}$.
\end{abstract}

Pulmonary nodules are commonly detected in patients with soft tissue sarcoma (STS) $(1,2)$, among which $20-30 \%$ develop pulmonary metastatic disease $(3,4)$. The detection of small pulmonary nodules has improved because of advancements in computed tomography (CT). Determining whether the pulmonary nodule is malignant or benign is important to evaluate the need for additional treatment such as surgical resection, chemotherapy, and radiotherapy. However, pulmonary nodules smaller than $5 \mathrm{~mm}$ are usually

Correspondence to: Tomoki Nakamura, Department of Orthopaedic Surgery, Mie University Graduate School of Medicine. 2-174 Edobashi, Tsu-city, Mie, 5148507, Japan. Tel: +81 592315022, Fax: +81 592315211, e-mail: tomoki66@clin.medic.mie-u.ac.jp

Key Words: FDG, PET, PET/CT, soft tissue sarcoma, pulmonary metastases. too small for obtaining sufficient material for an accurate pathological diagnosis, even if these nodules were detected (1). Particularly, the detection of pulmonary metastases smaller than $5 \mathrm{~mm}$ remains a problem due to difficulty in diagnosis $(5,6)$.

Recently, positron emission tomography (PET) with ${ }^{18} \mathrm{~F}$ fluorodeoxyglucose (FDG), a glucose analog, has also been increasingly used for screening patients. The sensitivity of CT, FDG-PET, and FDG-PET/CT in diagnosing pulmonary nodules has been 93\%, 69\%, and 97\%, respectively (7). However, Fortes et al. reported that only $44 \%$ of metastatic pulmonary nodules could be detected positively by FDGPET/CT (8). FDG-PET sensitivity can also be affected by the size of the metastatic pulmonary nodule (9). In patients with STS, the accuracy of FDG-PET/CT in detecting metastatic pulmonary nodules remains unclear. Therefore, this study aimed to elucidate the accuracy of FDG-PET/CT for pulmonary nodules in patients with STS.

\section{Materials and Methods}

Patients. A total of 102 patients, who had both chest CT and FDGPET/CT scans and had primary STS that was treated with surgical resection at our institution between April 2001 and December 2014, were retrospectively reviewed. Their clinical records and chest CT and FDG-PET/CT scans were reviewed to determine the presence of pulmonary nodules. If pulmonary nodules were present, the number, size, and distribution were determined. Patients with either hydrothorax or atelectasis were excluded from further analysis because it was difficult to evaluate the nodules in such conditions. This study was approved by the institutional review board of our institution. Informed consent was waived because of the nature of retrospective study. The design and procedures were carried out in accordance with the principles of the Declaration of Helsinki.

$F D G-P E T / C T$. All patients with pulmonary nodules were evaluated by PET/CT scans (Discovery PET/CT 690, GE Healthcare BioSciences, Pittsburgh, PA, USA, and Toshiba Aquiduo, Toshiba, Tokyo, Japan). PET/CT images of the head, neck, chest, and abdomen to at least the level of the iliac crest were obtained $60 \mathrm{~min}$ after intravenous injection of $3.7 \mathrm{MBq} / \mathrm{kg}$ FDG. The images were independently reviewed by experienced oncologists and radiologists 
(T.H., T.N., K.A., and Y.S.). The nodules were first examined visually for FDG accumulation, and the standardized uptake value (SUV) of all nodules was determined. Maximum SUV ( $\left.\mathrm{SUV}_{\max }\right)$ was defined as the peak SUV on 1 pixel with the highest count within the region of interest.

Diagnosis of pulmonary nodules. The pulmonary nodules were carefully categorized into two groups. Group A included metastatic pulmonary nodules, and Group B benign pulmonary nodules. Primary lung cancer was detected in one patient with STS; thus, the patient was also excluded from the study. The clinical decision on diagnosing the pulmonary nodules was based on the following criteria (10). A "metastatic pulmonary nodule" was defined when one or more of the following were satisfied: the histological diagnosis of a metastatic nodule was confirmed using specimens obtained by either CT-guided needle biopsy or surgical resection, or the nodules showed an obvious progression in number and/or size within 6 months. Typical findings of metastatic pulmonary nodules with and without FDG accumulation are shown in Figures 1 and 2, respectively. A "benign pulmonary nodule" was defined when one or more of the following were satisfied: the histological diagnosis of a benign nodule was confirmed using specimens obtained by CTguided needle biopsy or surgical resection, or the nodules showed no progression for at least 6 months or disappeared.

Statistical analysis. Accuracy was calculated as the sum of truepositive or true-negative pulmonary nodules divided by the total number of pulmonary nodules. Statistical associations between clinicopathological factors were evaluated using the Mann-Whitney $U$-test and Kruskal-Wallis test for quantitative data. Correlations between pulmonary nodule size and $\mathrm{SUV}_{\max }$ were tested using Spearman's rank correlation analysis. A significant Spearman's @ implied a correlation in the population. Receiver operating characteristic (ROC) curve analysis was performed to determine the threshold size of pulmonary nodules and SUV for the assessment of malignant pulmonary nodules. A value of $p<0.05$ was considered significant in all statistical analyses. All statistical analyses were performed using the EZR graphical user interface (Saitama Medical Center, Jichi Medical University, Saitama, Japan) for R (The R Foundation for Statistical Computing, Vienna, Austria), which is a modified version of $\mathrm{R}$ Commander designed to add statistical functions frequently used in biostatistics.

\section{Results}

Identifying the clinical characteristics of pulmonary nodules to distinguish metastatic from benign nodules. In 36 out of 102 patients (35.3\%) with STS, 212 pulmonary nodules were detected on CT scan alone. Among them, 35 patients had high-grade tumors and 1 had a low-grade malignant peripheral nerve sheath tumor. The median size of the 212 pulmonary nodules was $7.2 \mathrm{~mm}$ (range $=0.7-46 \mathrm{~mm}$ ). A total of 176 nodules were categorized under Group A, and 36 nodules under Group B. In Group A, 33 nodules were histologically diagnosed as metastatic nodules, while 143 showed an obvious progression in size within 6 months. In Group B, 8 nodules were histologically diagnosed as benign nodules, while 28 showed no progression for at least 6
Table I. The relationship between histology and characteristics of pulmonary nodules.

\begin{tabular}{lcc}
\hline Histology & \multicolumn{2}{c}{ Pulmonary nodule } \\
\cline { 2 - 3 } & $\begin{array}{c}\text { Metastasis } \\
\text { (nodule with } \\
\text { FDG positive) }\end{array}$ & $\begin{array}{c}\text { Benign } \\
\text { (nodule with } \\
\text { FDG positive) }\end{array}$ \\
\hline Leiomyosarcoma & $66(49)$ & $6(0)$ \\
UPS & $94(47)$ & $5(0)$ \\
Synovial sarcoma & $10(4)$ & $6(0)$ \\
MPNST & $1(1)$ & $6(1)$ \\
Dedifferentiated liposarcoma & $3(3)$ & $6(0)$ \\
Clear cell sarcoma & $0(0)$ & $3(0)$ \\
Myxofibrosarcoma & $0(0)$ & $3(0)$ \\
Epithelioid sarcoma & $2(1)$ & $0(0)$ \\
Hemangioendothelioma & $0(0)$ & $1(0)$ \\
Total & $176(105)$ & $36(1)$ \\
\hline
\end{tabular}

UPS: Undifferentiated pleomorphic sarcoma; MPNST: malignant peripheral nerve sheath tumor.

Table II. Relationships between the size of pulmonary nodules and diagnosis.

\begin{tabular}{|c|c|c|c|}
\hline \multirow[t]{2}{*}{ Clinical details } & \multicolumn{2}{|c|}{ Final diagnosis of pulmonary nodules } & \multirow[t]{2}{*}{$p$-Value } \\
\hline & $\begin{array}{c}\text { Metastatic } \\
\text { pulmonary } \\
\text { nodules }(n=176)\end{array}$ & $\begin{array}{c}\text { Benign } \\
\text { pulmonary } \\
\text { nodules }(n=36)\end{array}$ & \\
\hline \multicolumn{4}{|l|}{ Nodule size } \\
\hline$>5 \mathrm{~mm}$ & 100 & 4 & \\
\hline $1-5 \mathrm{~mm}$ & 76 & 32 & \\
\hline Range & $0.7-46.0 \mathrm{~mm}$ & $1.0-21.3 \mathrm{~mm}$ & \\
\hline Average & $7.9 \mathrm{~mm}$ & $3.8 \mathrm{~mm}$ & $<0.0001$ \\
\hline
\end{tabular}

months or disappeared. Correlations between histological diagnosis and characteristics of pulmonary nodules are shown in Table I. In the 176 metastatic nodules, FDG$\mathrm{PET} / \mathrm{CT}$ was positive in 105 nodules (59.7\%) and negative in $71(40.3 \%)$. In the 36 benign pulmonary nodules, FDGPET/CT was positive in $1(2.8 \%)$ and negative in 35 $(97.2 \%)$. Larger pulmonary nodules were likely to be metastatic $(p<0.0001$, Table II). The mean size of metastatic nodules was $7.9 \mathrm{~mm}$ (range $=0.7-46.0 \mathrm{~mm})$, compared with $3.8 \mathrm{~mm}$ (range $=1.0-21.3 \mathrm{~mm}$ ) for benign nodules. $\mathrm{SUV}_{\max }$ was significantly related to the diagnosis of nodules (benign $v s$. metastasis $)(p<0.0001)$. The mean value of $\mathrm{SUV}_{\max }$ in metastatic nodules was 2.4 (range $=0-19.5$ ), compared with 0.1 (range $=0-5$ ) in benign nodules. Pulmonary nodule size was strongly correlated with $\mathrm{SUV}_{\max }$ based on Spearman's rank correlation test (Spearman's $Q=0.771, p<0.0001$ ). The 


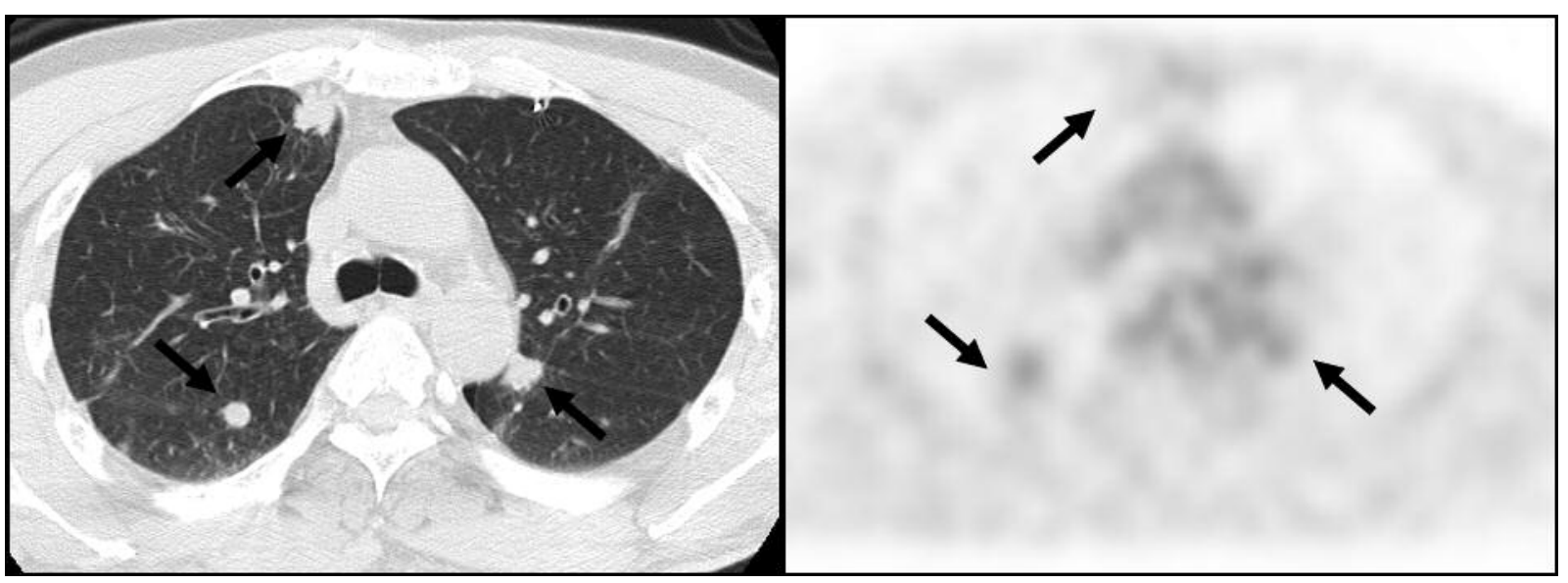

Figure 1. Typical findings of pulmonary nodules (arrow) with FDG accumulation. The nodules increased in number and/or size and thus were diagnosed as metastatic. Left: CT scan; Right: PET.
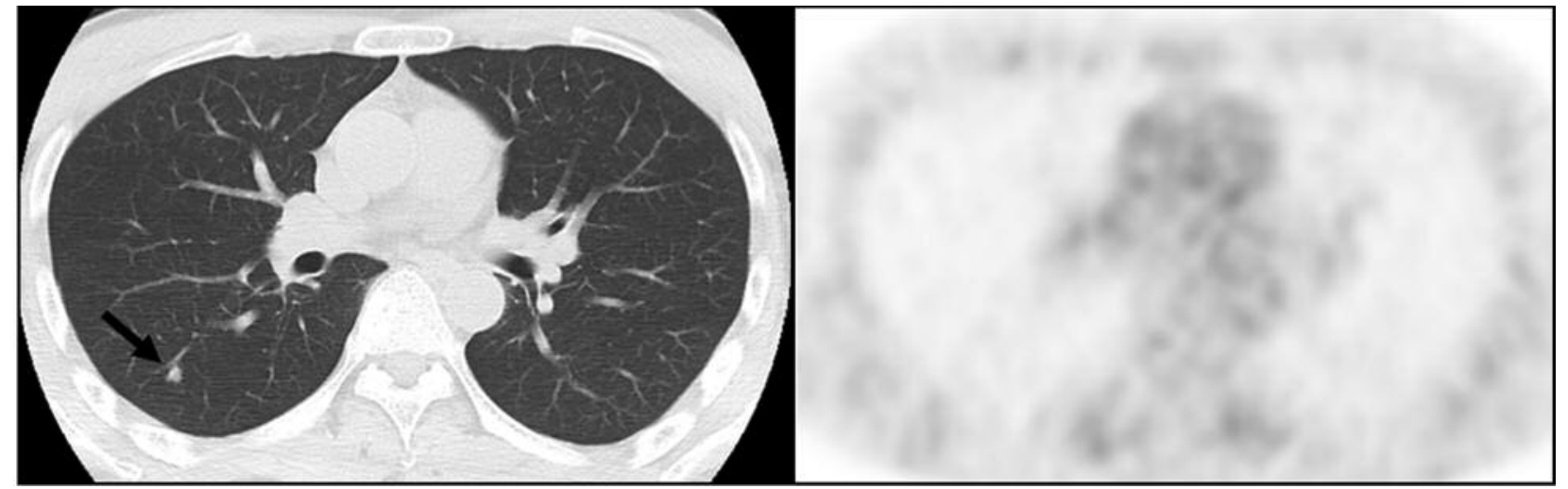

Figure 2. Typical findings of pulmonary nodules (arrow) without FDG accumulation. Nodule size did not change for 1 year; thus, the nodules were diagnosed as benign. Left: CT scan; Right: PET.

one nodule with a size of $11.7 \mathrm{~mm}$ that was categorized as benign in the patient with malignant peripheral nerve sheath tumor had an $\mathrm{SUV}_{\max }$ of 5.0. The benign pulmonary nodule in the patient with malignant peripheral nerve sheath tumor showed no progression in size for 5 years.

On ROC curve analysis, the optimal threshold for identifying a nodule at risk for a diagnosis of metastatic pulmonary nodule was $4.7 \mathrm{~mm}$. The area under the curve (AUC) was 0.782 (95\% confidential interval $[\mathrm{CI}]=0.699$ $0.865)$. At this threshold, pulmonary nodule size exhibited a sensitivity and specificity of $63.1 \%$ and $88.9 \%$, respectively, for predicting metastasis. Concerning the analysis of $\mathrm{SUV}_{\text {max }}$, the optimal threshold for identifying a nodule at risk for a diagnosis of metastatic pulmonary nodule was 0.9 . The AUC was $0.781(95 \% \mathrm{CI}=0.732-0.83)$. At this threshold, the $\mathrm{SUV}_{\max }$ of the pulmonary nodule exhibited a sensitivity and specificity of $59.7 \%$ and $97.2 \%$, respectively, for predicting malignancy.

Analysis of pulmonary nodules smaller than $5 \mathrm{~mm}$ using $F D G-P E T / C T$. As shown in Table II, there were 76 metastatic pulmonary nodules and 32 benign pulmonary nodules smaller than $5 \mathrm{~mm}$. Here, pulmonary nodule size smaller than $5 \mathrm{~mm}$ was weakly correlated with $\mathrm{SUV}_{\max }$ based on Spearman's rank correlation test (Spearman's $\varrho=0.394, p<0.0001)$. Regarding nodules smaller than $5 \mathrm{~mm}$, only 10 out of 76 metastatic pulmonary nodules $(13.2 \%)$ showed FDG accumulation, and none of the accumulations were shown in benign pulmonary nodules. Relationships between FDG accumulation of pulmonary nodules and 
diagnosis are shown in Table III. FDG accumulation exhibited a sensitivity, specificity, and accuracy of $59.7 \%, 97.2 \%$, and $66.0 \%$, respectively, for all pulmonary nodules regardless of diagnosis. Meanwhile, for the diagnosis of nodules smaller than $5 \mathrm{~mm}$, FDG accumulation exhibited a sensitivity, specificity, and accuracy of $13.2 \%, 100.0 \%$, and $38.9 \%$, respectively. For the diagnosis of nodules larger than $5 \mathrm{~mm}$, FDG accumulation exhibited a sensitivity, specificity, and accuracy of $95.0 \%, 75.0 \%$, and $94.2 \%$, respectively (Table IV).

\section{Discussion}

The lung is the most common site of metastasis of STS (8), and several studies have shown that CT scan is the most appropriate technique to detect pulmonary metastases. In this study, nodule size was a predictive factor for diagnosis. The malignancy rate was higher in patients with nodules larger than $5 \mathrm{~mm}$, and the optimal threshold for identifying metastasis was $4.7 \mathrm{~mm}$. Meanwhile, the detection of metastatic pulmonary nodules smaller than $5 \mathrm{~mm}$ remains a problem because of difficulty in diagnosis $(5,6)$.

Recent attention has focused on FDG-PET as a diagnostic tool for pulmonary nodules (11). Several reports have suggested that FDG-PET/CT examinations reduce the number of patients with indeterminate nodules undergoing unnecessary surgical biopsy $(12,13)$. Therefore, here, the accuracy of FDG-PET/CT was evaluated as a possible tool for diagnosing pulmonary nodules in patients with STS. The degree of FDG activity is directly associated with glucose metabolism, which is increased in malignant cells (14). Pulmonary nodules have been shown to overexpress glucose transporter protein type 1

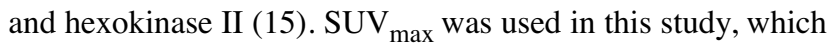
is the most widely used semiquantitative parameter in measuring the radioactivity of the imaging agent in the tumor (16). Metabolic tumor volume is another semiquantitative parameter that integrates metabolism and volume (17), while total lesion glycolysis represents the tumor's malignant transformation (16). However, $\mathrm{SUV}_{\max }$ is regarded as a limited parameter that can only represent the tumor activity but fails to signify the whole tumor volume (18). In the present study, the mean value of $\mathrm{SUV}_{\text {max }}$ in metastatic nodules was 2.4 (range=0-19.5), which was significantly higher than that in benign nodules $(0.1$; range $=0-5)$. Furthermore, this study demonstrated a strong correlation between pulmonary

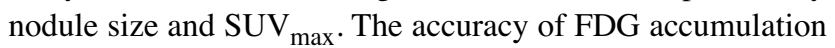
for all pulmonary nodules was $66.0 \%$, with a sensitivity of $59.7 \%$. Regarding pulmonary nodules smaller than $5 \mathrm{~mm}$, the accuracy was only $38.9 \%$, with a sensitivity of $13.2 \%$, although for nodules larger than $5 \mathrm{~mm}$, the accuracy was $94.2 \%$, with a sensitivity of $95.0 \%$. This suggests that FDG$\mathrm{PET} / \mathrm{CT}$ is not sufficient to diagnose pulmonary metastasis of STS, especially with small nodules. Therefore, FDG-PET/CT may be limited in making a differential diagnosis between
Table III. Relationships between FDG accumulation of the pulmonary nodules smaller than $5 \mathrm{~mm}$ and diagnosis.

\begin{tabular}{lccc}
\hline FDG accumulation & $\begin{array}{c}\text { Metastatic } \\
\text { pulmonary } \\
\text { nodules }(\mathrm{n}=76)\end{array}$ & $\begin{array}{c}\text { Benign } \\
\text { pulmonary } \\
\text { nodules }(\mathrm{n}=32)\end{array}$ & $p$-Value \\
\hline Positive & 10 & 0 & 0.03 \\
Negative & 66 & 32 & \\
\hline
\end{tabular}

Table IV. Relationships between FDG accumulation of the pulmonary nodules larger than $5 \mathrm{~mm}$ and its diagnosis.

\begin{tabular}{lccc}
\hline FDG accumulation & $\begin{array}{c}\text { Metastatic } \\
\text { pulmonary } \\
\text { nodules }(\mathrm{n}=100)\end{array}$ & $\begin{array}{c}\text { Benign } \\
\text { pulmonary } \\
\text { nodules }(\mathrm{n}=4)\end{array}$ & $p$-Value \\
\hline Positive & 95 & 1 & 0.002 \\
Negative & 5 & 3 & \\
\hline
\end{tabular}

metastatic and benign nodules when the nodule size is smaller than $5 \mathrm{~mm}$. The results further suggest that $\mathrm{CT}$ scan remains the standard diagnostic tool for detecting and diagnosing small pulmonary lesions. Further study is necessary to validate it.

This study has certain limitations. Firstly, a misdiagnosis may occur for pulmonary lesions that are clinically diagnosed as benign. Some small pulmonary nodules with extremely long tumor doubling time, which were diagnosed as benign, might be metastatic sarcomas, although the doubling time of high-grade sarcomas is usually short (19). Secondly, SUV varies with several factors. FDG uptake may differ from the interval between tracer injection and the start of the scan, although our institution standardized $60 \mathrm{~min}$ as the time interval; otherwise, the blood glucose level might influence the results. Lastly, this study has a retrospective nature.

In conclusion, the role of FDG-PET/CT in differentiating metastatic from benign pulmonary nodules was unsatisfactory, especially for small nodules. Careful followup using CT scan may still be appropriate in diagnosing pulmonary nodules smaller than $5 \mathrm{~mm}$.

\section{References}

1 Nakamura T, Matsumine A, Niimi R, Matsubara T, Kusuzaki K, Maeda M, Tagami T and Uchida A: Management of small pulmonary nodules in patients with sarcoma. Clin Exp Metastasis 26: 713-718, 2009.

2 Billingsley KG, Burt ME, Jara E, Ginsberg RJ, Woodruff JM, Leung DH and Brennan MF: Pulmonary metastases from soft tissue sarcoma. Ann Surg 229: 602-612, 1999.

3 Liebl LS, Elson F, Quaas A, Gawad KA and Izbicki JR: Value of repeat resection for survival in pulmonary metastases from soft tissue sarcoma. Anticancer Res 27: 2897-2902, 2007. 
4 Lowe VJ and Naunheim KS: Current role of positron emission tomography in thoracic oncology. Thorax 53: 703-712, 1998.

5 De Wever W, Meylaerts L, De Ceuninck L, Stroobants S and Verschakelen JA: Additional value of integrated PET-CT in the detection and characterization of lung metastases: correlation with CT alone and PET alone. Eur Radiol 17: 467-473, 2007.

6 Diederich S, Semik M, Lentschig MG, Winter F, Scheld HH, Roos N and Bongartz G: Helical CT of pulmonary nodules in patients with extrathoracic malignancy: CT-surgical correlation. AJR AM J Roentgenol 172: 353-360, 1999.

7 Kim SK, Allen-Auerbach M, Goldin J, Fueger BJ, Dahlbom M, Brown M, Czernin J and Schiepers C: Accuracy of PET/CT in characterization of solitary pulmonary lesion. J Nucl Med 48: 214-220, 2007.

8 Fortes DL, Allen MS, Lowe VJ, Shen KR, Wigle DA, Cassivi SD, Nichols FC and Deschamps C: The sensitivity of ${ }^{18} \mathrm{~F}$ fluorodeoxyglucose positron emission tomography in the evaluation of metastatic pulmonary nodules. Eur J Cardiothorac Surg 34: 1223-1227, 2008

9 Gould MK, Maclean CC, Kuschner WG, Rydzak CE and Owens DK: Accuracy of positron emission tomography for diagnosis of pulmonary nodules and mass lesions: a meta-analysis. JAMA 285: 94-924, 2001.

10 Lagaru A, Chawla S, Menendez L and Conti PS: ${ }^{18}$ F-FDG PET and PET/CT for detection of pulmonary metastases from musculoskeletal sarcomas. Nucl Med Commun 27: 795-802, 2006.

11 Sarinas PS, Chitkara RK, Buadu EO, Gould MK, Kuschner WG and Segall GM: Usefulness of positron emission tomography imaging in the management of lung cancer. Curr Opin Pulm Med 5: 201-207, 1999.

12 Chen YK, Ding HJ, Su CT, Shen YY, Chen LK, Liao AC, Hung $\mathrm{TZ}, \mathrm{Hu} \mathrm{FL}$ and Kao $\mathrm{CH}$ : Application of PET and PET/CT imaging for cancer screening. Anticancer Res 24: 4103-4108, 2004

13 Gambhir SS, Shepherd JE, Shah BD, Hart E, Hoh CK, Valk PE, Emi T and Phelps ME: Analytical decision model for the costeffective management of solitary pulmonary nodules. J Clin Oncol 16: 2113-2125, 1998.
14 Kaira K, Okumura T, Ohde Y, Takahashi T, Murakami H, Oriuchi N, Endo M, Kondo H, Nakajima T and Yamamoto N: Correlation between ${ }^{18} \mathrm{~F}-\mathrm{FDG}$ uptake on PET and molecular biology in metastatic pulmonary tumors. J Nucl Med 52: 705711, 2011.

15 Mamede $M$, Higashi $T$, Kitaichi $M$, Ishizu $K$, Ishimori $T$, Nakamoto Y, Yanagihara K, Li M, Tanaka F, Wada H, Manabe $\mathrm{T}$ and Saga T: ${ }^{18} \mathrm{~F}-\mathrm{FDG}$ uptake and PCNA, Glut-1, and hexokinase-II expressions in cancers and inflammatory lesions of the lung. Neoplasia 7: 369-379, 2005.

16 Jaskowiak CJ, Bianco JA, Perlman SB and Fine JP: Influence of reconstruction iterations on ${ }^{18} \mathrm{~F}-\mathrm{FDG} \mathrm{PET} / \mathrm{CT}$ standardized uptake values. J Nucl Med 46: 424-428, 2005.

17 Biehl KJ, Kong FM, Dehdashti F, Jin JY, Mutic S, El Naqa I, Siegel BA and Bradley JD: ${ }^{18}$ F-FDG PET definition of gross tumor volume for radiotherapy of non-small cell lung cancer: is a single standardized uptake value threshold approach appropriate? J Nucl Med 47: 1808-1812, 2006.

18 Chang KJ, Lim I, Park JY, Jo AR, Kong CB, Song WS, Jo WH, Lee SY, Koh JS, Kim BI, Choi CW and Lim SM: The role of (18)F-FDG PET/CT as a prognostic factor in patients with synovial sarcoma. Nucl Med Mol Imaging 49: 1836-1842, 2015.

19 Nakamura T, Matsumine A, Niimi R, Matsusaka M, Mizumoto K, Mori M, Yoshizaki T, Matsubara T, Asanuma K and Sudo A: Analysis of pulmonary nodules in patients with high-grade soft tissue sarcomas. PLoS One, 2017. doi: 10.1371/ journal.pone.0172148
Received March 5, 2018

Revised April 5, 2018

Accepted April 5, 2018 